\title{
Developing Effective English Language Teaching Strategies for Non-Native English Speaking Dyslexic Students
}

\author{
Dr. Rishi Mishra ${ }^{1}$, Dr. Mohammad Ashraf Shah ${ }^{2}$
}

\section{ABSTRACT}

Dyslexia, or specific reading disability, is a disorder in which children with normal intelligence and sensory abilities show learning deficits for reading. The developments in reading lags behind other academic developments. Achieved reading skill is limited. Reading is slow and non-word reading is impaired. The educational system has difficulties in understanding dyslexia and an even harder time identifying children with dyslexia in order to provide the correct intervention for students who are non - native English speakers. When a school has the added challenge of identifying struggling English language learners (ELLs), the task becomes an even more complicated process, and often, these kids are completely missed. But that does not have to be the case. Children who are learning English are just as likely to have dyslexia as their nativeEnglish-speaking counterparts, and there is a way to identify dyslexia in these children. The difference is that dyslexia might appear in the native language quite as vividly as it will when they attempt to learn English. This research paper tries to analyze those teaching strategies which have been very effective in developing English language skills among the non native speakers. It reviews the body of research on difficulties faced by dyslexic students in educational setup and different teaching methods which played an effective role in enhancing the English language learning skills of the students. First, we explore the assessment of comprehension and reading difficulties of these students at initial stages. Next we discuss the methodology used in reviewing the literature on different instructional methods for the students with specific focus on dyslexic students.

Keywords: English language learners, Specific Learning disability, Dyslexia

Dyslexia affects up to 20\% of the population of those who read English; that's one in five people (Shaywitz, 2005)[1]. However, Snowling (2000) suggested that when the language is more transparent than English, such as Spanish, Finnish, and German, that number decreases to

\footnotetext{
${ }^{1}$ Visiting Faculty, Amity Institute of Psychology and Allied Sciences, Amity University, Noida, India

${ }^{2}$ Lecturer, Govt. Degree College, Sopore, Kashmir, India

*Responding Author

(C) 2016 I R Mishra, M Shah; licensee IJIP. This is an Open Access Research distributed under the terms of the Creative Commons Attribution License (http://creativecommons.org/licenses/by/2.0), which permits unrestricted use, distribution, and reproduction in any Medium, provided the original work is properly cited.
} 


\section{Developing Effective English Language Teaching Strategies for Non-Native English Speaking Dyslexic Students}

about 5\%. [2] Therefore, when we broaden the discussion to include the ELL, we must remember that dyslexia is a human condition that is not bound by country, it has no language borders, and it can affect anyone attempting to decode a printed alphabetic language (and probably a logographic language as well). It is still worth establishing that dyslexia is not a result of laziness, lack of motivation, or socioeconomic advantage or disadvantage. Contrary to popular belief and the rampant misinformation distributed, dyslexia is not a visual problem, even though it may present itself that way when students appear to be transposing letters like b, d, p, and q. The fact is that students with dyslexia see letters and words the same way those of us without dyslexia do. This brings us to the definition of dyslexia.

Dyslexia is an often-misunderstood, confusing term for reading problems. The word dyslexia is made up of two different parts: dys meaning not or difficult, and lexia meaning words, reading, or language. So quite literally, dyslexia means difficulty with words. It is a specific learning disability that is neurological in origin. It is characterized by difficulties with accurate and/or fluent word recognition and by poor spelling and decoding abilities. These difficulties typically result from a deficit in the phonological component of language that is often unexpected in relation to other cognitive abilities and the provision of effective classroom instruction. Secondary consequences may include problems in reading comprehension and reduced reading experience that can impede the growth of vocabulary and background knowledge.

\section{Beginning stages}

Traits of Dyslexia start being obvious by age three and although can often be mistaken for a normal development time table that is different for all children, clusters of these issues can start to stand out from other children. As children mature and become adults their "Dyslexia" doesn't go away; they hopefully learn to work with it and accommodate themselves. Other children are not so lucky. Some are successful adapting to a left-brained world and others are plagued with their "learning differences" having no guidance to deal with them. A lot of these indicators or traits occur with other health and mental issues or personality types that are not Dyslexia. [3]

Dyslexics are dominant right brain learners and thinkers in a society that reflects and respects the thinking processes of the left brain. "Righties" can have a difficult time fitting in. This list of indicators and traits are about the particular view of the world common to righties that can create issues for them. This is not to say that being a left-brain thinker is better

\section{Dyslexia and Language}

Ask the average person on the street what dyslexia is, and you will get a plethora of incorrect and absurd responses. In order to begin to understand what it might be like to have dyslexia, take a moment to read the following sentence: 


\section{Developing Effective English Language Teaching Strategies for Non-Native English Speaking Dyslexic Students}

The bottob line it thit it doet exitt, no bitter whit nibe teotle give it (i.e. ttecific leirning ditibility, etc). In fict, iccording to Tilly Thiywitz (2003) itt trevilence it ictuilly one in five children, which it twenty tercent.

When most people think of dyslexia, they think of people seeing letters and words backwards; like seeing $b$ as $d$ and $d$ as $b$. But despite a great amount of effort and intellectual capability, dyslexic people experience the slow, laborious pace you just experienced, yet they experience it every time they read. They are not only highly motivated, but very adept at adapting and accommodating their dyslexia in brilliant ways. Dyslexia is a phonological processing problem that is neurobiological and makes it difficult to decode words accurately and fluently, as well as making spelling very difficult. Dyslexia is highly genetic and occurs on a continuum from mild to severe. People with dyslexia have the ability to learn to read, they just need to be taught the way they learn, and they require accommodations to succeed via other learning modalities, such as the audio presentation of information.

Dyslexia affects humans, not English readers, and this means that students in classrooms who are struggling to learn English may be at risk for dyslexia. More often than not, these students may be missed, because it is assumed that because the English language is complicated and opaque, the student is having difficulty learning it but will eventually get it. This is erroneous. While English is not as transparent as Spanish or German, it is not the language that is causing the struggle. It is the dyslexia. There are ways to determine if the student is having difficulty due to dyslexia.

A significant factor which affects language acquisition is orthographic depth. The orthographic depth hypothesis, which is well known to linguists and informed educationalists, proves that the more complex or 'deep' the orthography of a language the more difficult it will be to learn. A transparent language is one which has a very clear letter-sound correspondence and much regularity. In contrast, a deep or opaque language is one which has a more complex phonemegrapheme correspondence and more irregularities. English is one of the most complex languages, and while Irish orthography is not as deep as English, it is not considered to be a transparent language. In European terms, Finnish is considered the most transparent European language. Spanish and Italian are also quite transparent; French and Danish are more opaque as is English [4]. The orthographic depth hypothesis clearly explains why students can learn some languages more readily than others - this applies to all students, but in particular those with dyslexia and other language acquisition difficulties. Therefore, evidence shows that these

students should logically opt for a more transparent language when choosing an additional language to learn, in order to minimize the impact of their diagnosed learning difficulty. 


\section{Developing Effective English Language Teaching Strategies for Non-Native English Speaking Dyslexic Students}

The answer lies in the students' abilities in their native languages and the investigation should begin there. The first step is to determine if dyslexia is a possibility, so the students' ability to verbally manipulate the sounds in their native languages, otherwise known as phonemic awareness, must be assessed. Brown (2008) suggested that students with below-average phonemic awareness in their native languages will have difficulty learning a new language. If the student is not literate in his native language, he can still be tested for phonemic awareness. Secondly, the reading fluency and spelling of those students whose native languages are a transparent languages, such as Spanish, need to be assessed. Fluency and orthography issues are red flags for dyslexia. This is in contrast to those native English speakers who are usually identified by their difficulty in decoding new and unfamiliar words, but this difficulty is a better predictor of reading difficulties in English, because it is an opaque language. So those students who have transparent native languages will have less difficulty sounding out words, because the languages are predictable; therefore, when the fluency is low in the native language, there is a problem with reading. Third, rapid automatic naming or RAN is a predictor of reading difficulties in ELLs and should be part of the assessment. RAN tests the students' ability to rapidly name items, letters, or numbers that are presented to them visually. Lastly, dyslexia is highly genetic, so, if possible and relevant, the family's history of reading success should be surveyed. [5]

This is the neat and tidy version of how to determine if an ELL student has dyslexia. Of course, identification of dyslexia in an ELL is a complicated procedure. Many factors need to be ruled out. For example, the lack of opportunity to learn in native languages or the lack of home support in learning English needs to be investigated. Also, does the child have the intellectual capability to learn to read at the same rate as her peers? Although it can be tricky to identify dyslexia in the ELL children, the intervention they should receive has the potential to help any child who is struggling with reading.

Reported that ELL students who are struggling to learn English and have some foundation in reading in their native language should receive direct instruction that includes speech perception, phoneme awareness, and sound-symbol connections. This is very similar to the OrtonGillingham approach that is recommended as the intervention for English readers who have dyslexia. Literacy in the students' initial language is really the key to helping them attain English, especially with dyslexia present. This might be seen as an insurmountable burden to a school system in which children speak a multitude of languages, but it is the most appropriate way to remediate the reading issue. However, in districts where there is a high concentration of one language, this is a very plausible solution. This strong foundation in their native language will translate into their English learning. McCardle et al (2005) reported that ELLs with reading disabilities were identified far later than their English-only peers, and this greatly impacts their ability to achieve their potential.[6] 


\section{Developing Effective English Language Teaching Strategies for Non-Native English Speaking Dyslexic Students}

Dyslexia and the ELL student is a very complex topic and creates a conundrum for educators. While the best way to identify and intervene seems completely financially and logistically implausible, simply on the basis of the number of languages spoken in any single school district, it is how to help the ELL who is dyslexic. The good news is that once a students master their native language, they will be able to achieve literacy in English, but we can't fail to see that those who are struggling with English might have a legitimate learning disability, like dyslexia, and might need an appropriate remediation in order to give them a fair chance. It is far too easy to allow these kids in particular to fall through the cracks.

\section{Student Strengths}

Educators recognize that students learn in different ways and have unique patterns of strengths and needs. For example, a student who is not doing well in reading may show an aptitude for other areas such as physical education, drama, or mathematics. Each student with a learning disability presents with his/her own learning style, needs, strengths, and interests. However, educators and parents may need to assist the student in identifying strengths and pursuing interests. It is important for students with learning disabilities to identify an interest, hobby, or an area in which they can excel. Students need to see themselves as having something important to say, and to have an activity in which they feel successful and view themselves as "winners". It is also important for students to have a clear understanding of their learning ability and disability. This understanding can provide the basis for building a positive self-image that will support the development of a competent and successful person. It may be helpful for parents and students to be aware of the many well-known successful people who have been diagnosed with a learning disability. [7].Some of these include the businessman, Charles Schwab; the actor, Tom Cruise; the comedian, Jay Leno; the singer, Jewel; and the author of Captain Underpants, Dav Pilkey. "Let the student's strengths and not the disability define who they are as a person" (Shaywitz, 2003).

\section{Strategies and Effective Practices}

Adaptations for Students with Receptive/Expressive Language Difficulties

1 Give students more time to respond verbally as it often takes them longer to process oral language. 2. Give students more time to read passages or fewer passages to read because they are typically slow readers. 3. Give students more time to complete written assignments as it often takes them longer to get their thoughts down on paper. 4. Provide clear and concise instructions. 5. Encourage students to paraphrase instructions. 7. Provide real life examples of verbal concepts. 8. Use cooperative learning teaching methods to allow students to utilize their strengths within a group. 9. Provide opportunities for peer tutoring. 10. Provide a reader and/or scribe when necessary.11. Provide models and writing samples for assignments. 12. Allow alternate formats of assignments. 13. Use a multi-sensory (auditory, visual, tactile, kinesthetic) instructional approach. 14. Use demonstrations and modeling to get information across to 


\section{Developing Effective English Language Teaching Strategies for Non-Native English Speaking Dyslexic Students}

students. 15. Pair students to check directions and instructions. - Provide a rich language environment with numerous opportunities to engage in small group listening and speaking activities. [7]

\section{Acknowledgments}

The author appreciates all those who participated in the study and helped to facilitate the research process.

\section{Conflict of Interests}

The author declared no conflict of interests.

\section{REFERENCE}

1. Sally E. Shaywitz, , Bennett A. Shaywitz Dyslexia (Specific Reading Disability), Biological Psychiatry, Volume 57, Issue 11, 1 June 2005, Pages 1301-1309.

2. Snowling, Margaret, D. V. M. Bishop, and Susan E. Stothard. "Is preschool language impairment a risk factor for dyslexia in adolescence?" Journal of Child Psychology and Psychiatry 41.05 (2000): 587-600.

3. Mishra R. \& Mohan A. Developments in effective teaching strategies for students with dyslexia: a review of literature and research, International Journal of Applied Research, IJAR June 2016; 2(6): 206-209

4. Seymour, Philip HK, Mikko Aro, and Jane M. Erskine. "Foundation literacy acquisition in European orthographies." British Journal of psychology 94.2 (2003): 143-174.

5. Frith, U., Wimmer, H., \& Landeri, K. (1998). Differences in phonological recoding in German- and English-speaking children. Journal of the Society for Scientific Study of reading, 2, 31-54.

6. McCardle, P., Mele-McCarthy, J., Cutting, L., Leos, K, \& D’Emilio, T. (2005). Learning disabilities in English language learners: Identifying the issues. Learning Disabilities Research \& Practice, 20, $1-5$.

7. Teaching Students with Reading Difficulties and Disabilities: A Guide for Educators

8. Mather \& Goldstein (2001); New Brunswick Department of Education (1999).

How to cite this article: R Mishra, M Shah (2016), Developing Effective English Language Teaching Strategies for Non-Native English Speaking Dyslexic Students, International Journal of Indian Psychology, Volume 3, Issue 4, No. 58, ISSN 2348-5396 (e), ISSN: 2349-3429 (p), DIP: 18.01.050/20160304, ISBN: 978-1-365-24976-1 